\title{
Case reports of two pedigrees with recessive arrhythmogenic right ventricular cardiomyopathy associated with homozygous Thr335Ala variant in DSG2
}

\author{
Sami Qadri' , Olli Anttonen², Juho Viikilä2 ${ }^{2}$ Eija H. Seppälä3, Samuel Myllykangas ${ }^{3,4}$, Tero-Pekka Alastalo ${ }^{3,5}$,
} Miia Holmström ${ }^{6}$, Tiina Heliö ${ }^{1}$ and Juha W. Koskenvuo ${ }^{3,6^{*}}$

\begin{abstract}
Background: Arrhythmogenic right ventricular cardiomyopathy (ARVC) is an inherited cardiac disease, involving changes in ventricular myocardial tissue and leading to fatal arrhythmias. Mutations in desmosomal genes are thought to be the main cause of ARVC. However, the exact molecular genetic etiology of the disease still remains largely inconclusive, and this along with large variabilities in clinical manifestations complicate clinical diagnostics.

Case presentation: We report two families $(n=20)$ in which a desmoglein-2 (DSG2) missense variant c.1003A > G, p.(Thr335Ala) was discovered in the index patients using next-generation sequencing panels. The presence of this variant in probands' siblings and children was studied by Sanger sequencing. Five homozygotes and nine heterozygotes were found with the mutation. Participants were evaluated clinically where possible, and available medical records were obtained. All patients homozygous for the variant fulfilled the current diagnostic criteria for ARVC, whereas none of the heterozygous subjects had symptoms suggestive of ARVC or other cardiomyopathies.

Conclusions: The homozygous DSG2 variant c.1003A > G co-segregated with ARVC, indicating autosomal recessive inheritance and complete penetrance. More research is needed to establish a detailed understanding of the relevance of rare variants in ARVC associated genes, which is essential for informative genetic counseling and rational family member testing.
\end{abstract}

Keywords: Arrhythmogenic right ventricular cardiomyopathy, Cardiomyopathies, Desmosomes, DSG2, Mutation, Case series

\section{Background}

Arrhythmogenic right ventricular cardiomyopathy (ARVC) is an inherited cardiac disorder, affecting predominantly the right and sometimes the left ventricle and is characterized by progressive fibro-fatty replacement of ventricular myocardial tissue [1-5]. Clinical manifestations include recurrent, typically exercise-related ventricular arrhythmias, syncope, heart failure and sudden cardiac death [6-8]. Initial presentation is generally at adoles-

\footnotetext{
* Correspondence: juha.koskenvuo@hus.fi

${ }^{3}$ Blueprint Genetics, Helsinki, Finland

${ }^{6}$ Department of Clinical Physiology and Nuclear Medicine, HUS Medical Imaging Center, Helsinki University Hospital and University of Helsinki, 00290 Helsinki, Finland

Full list of author information is available at the end of the article
}

cence or young adulthood [3]. Diagnosis is based on the revised 2010 Task Force Criteria (TFC) by Marcus et al., establishing complex requirements for right ventricular (RV) function and structure, electrocardiographic (ECG) findings and genetic or familial background of the disease [9]. Prevalence in the general population has been estimated to be from 1:5000 to 1:1000 [10,11].

Mutations in genes encoding cardiac desmosomal proteins are the major determinants of ARVC [12]. These include plakophilin-2 (PKP2), desmoplakin $(D S P)$, desmoglein-2 (DSG2), desmocollin-2 (DSC2) and plakoglobin $(J U P)$ genes [13]. The mode of inheritance is typically autosomal dominant with incomplete penetrance and variable expression [14]. Rare 
recessive forms may be seen either as sole cardiomyopathy or in conjunction with systemic cutaneous disorders with palmoplantar keratoderma and woolly hair [15-19]. Recent studies have revealed that cardiac desmosomal gene mutations also associate with dilated cardiomyopathy (DCM) phenotype [20, 21]. Mutations in the DSP gene explained $5.5 \%$ of DCM cases in a Finnish study cohort [22].

As much as $30-50 \%$ of ARVC patients carry at least one variant classified as disease causing [23, 24]. However, molecular genetic diagnostic yield is known to be highly variable, at least partly due to different variant classification practices. Variability in clinical manifestations, reduced penetrance and digenic inheritance, along with disease modifying lifestyle factors such as exercise act together in complicating the determination of conclusive inheritance patterns [25-28]. End-stage ARVC is also sometimes difficult to distinguish from DCM, with significantly overlapping morphology due to left ventricular (LV) involvement and apparent similarities in molecular genetic etiology [29]. Thus, more research is needed to reveal a group of genes associated with the ARVC phenotype, their inheritance patterns, and genotype-phenotype associations in the disease.

Here, we report two Finnish pedigrees $(n=20)$ in which a homozygous DSG2 variant c.1003A > G, p.(Thr335Ala) co-segregated with ARVC, indicating autosomal recessive inheritance and complete penetrance. All heterozygous mutation carriers were healthy in terms of cardiac disease, even though this variant has been previously described as disease causing in a heterozygous state.

\section{Case presentation}

The index patients of these two families fulfilled the revised diagnostic criteria for ARVC by Marcus et al. [9]. Family history was obtained and pedigrees were drawn. Our clinicians assessed the adult family members at Helsinki University Hospital or Päijät-Häme Central Hospital where possible by physical examination, resting 12lead ECG, signal-averaged electrocardiography (SAECG), appropriate laboratory tests and transthoracic echocardiography or cardiac magnetic resonance imaging (MRI). From those already deceased, we acquired all available hospital records concerning cardiac diseases. The clinical diagnoses of the family members were also based on the 2010 TFC. All participants are of Finnish ethnicity.

\section{Molecular genetic studies}

Blueprint Genetics carried out genetic testing using targeted sequencing panels utilizing oligonucleotide-selective sequencing (OS-Seq) [30]. Family 1 proband's genetic evaluation was performed using the Pan Cardiomyopathy Panel, covering 103 genes associated with pediatric and adult onset cardiomyopathies and their phenocopies.
Family 2 proband was genetically evaluated using the Heart Panel, covering 133 genes associated with cardiomyopathies and hereditary arrhythmias. An additional file describes these next generation sequencing (NGS) based panels in more detail (see Additional file 1). Our variant filtering scheme is outlined in Fig. 1. We studied the presence of Thr335Ala in DSG2 in probands' relatives by bi-directional Sanger sequencing.

\section{Family screening}

We found both probands to be homozygous for the missense variant c.1003A > G, p.(Thr335Ala), (rs191564916) in DSG2. In silico predictions for this variant are contradictory, as it is predicted to be damaging by PolyPhen [31] and Mutation Taster [32] but tolerated by SIFT [33]. There is one heterozygous carrier of the variant in the 1000 Genomes Project [34] and a total of 67 carriers in the Exome Aggregation Consortium database (ExAC, $n=60,275)$ [35]. The p.(Thr335Ala) in DSG2 is fairly common especially among the Finnish population as six

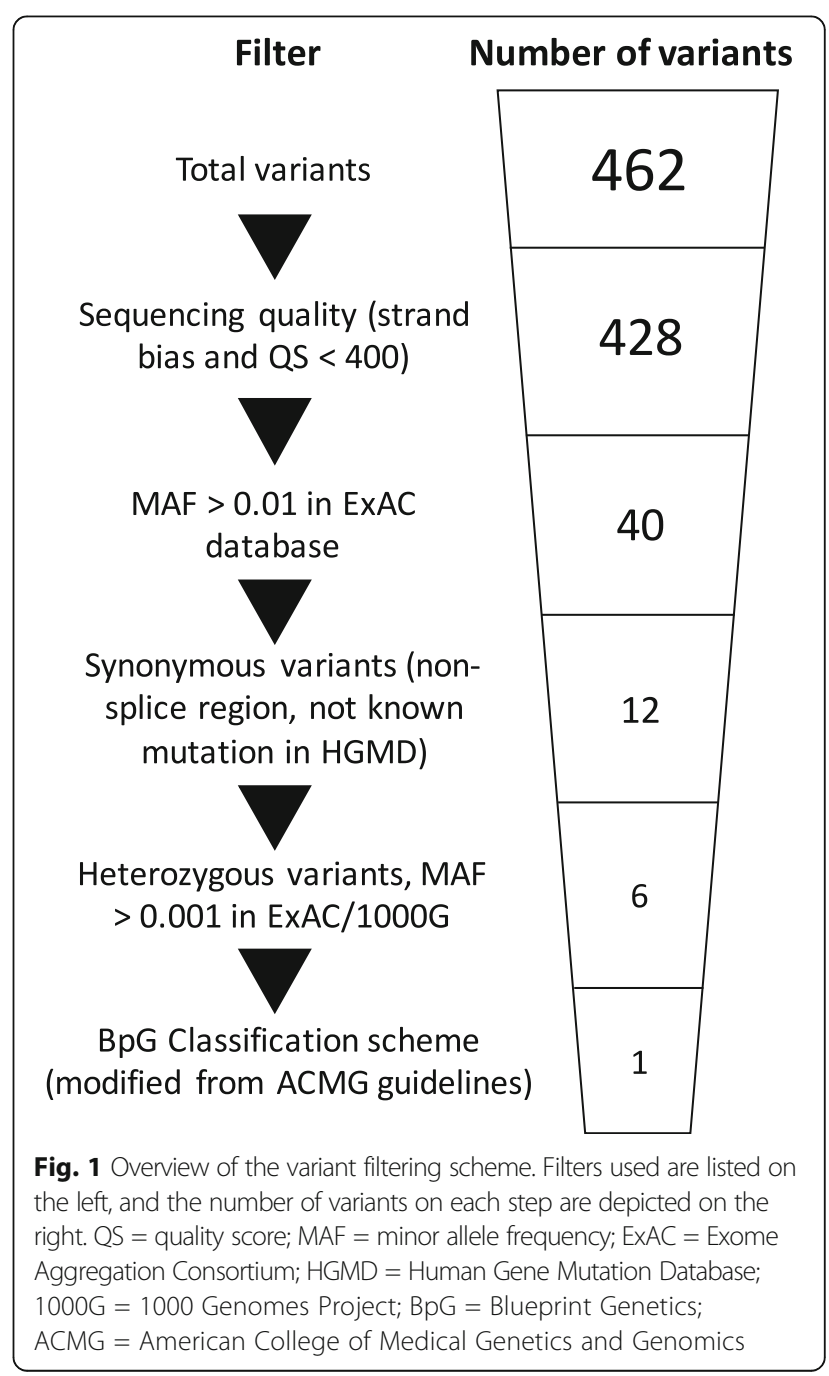


of the carriers were from Finland $(\mathrm{n}(\mathrm{FIN})=3304)$. However, there are no homozygote individuals in the ExAC control cohorts.

We present five homozygotes and nine heterozygotes older than 20 years from two families with this variant. The main clinical characteristics of the subjects are shown in Table 1. Pedigrees of families 1 and 2 are demonstrated in Fig. 2.

\section{Family 1}

Proband (II.3) is a 52-year-old male with clinical suspicion of ARVC. He had recurrent episodes of sustained ventricular tachycardia (VT) and a collapse, with the onset of symptoms at age 42. Electrophysiological study (EPS) revealed a large scar in the RV wall, and a hemodynamically unstable VT of right ventricular outflow tract (RVOT) origin was inducible. Cardiac MRI showed no abnormalities at the time of initial investigations. During the follow-up, RV enlargement was noted, and mild LV dilatation occurred without changes in systolic function or wall thickness. RV ejection fraction (EF) was diminished. Patient has an implantable cardioverter defibrillator (ICD), and is treated with betablockers.

Proband's sister (II.5) is a 54-year-old female with an initial presentation of acute-onset VT with angina pain and elevated cardiac markers at age 37. Angiography reveled a coronary artery stenosis which was thought to be the culprit lesion, and percutaneous coronary intervention (PCI) was performed successfully. Thereafter, patient had recurrent events of sustained VT with no associated cardiac marker elevations and ICD was implanted. Patient later suffered an ST-elevation myocardial infarction with another PCI performed. Catheter ablation was done with no reduction in arrhythmic episodes. During the follow up, no change in LV diameter was noted, but the right ventricle underwent marked dilatation. Patient also suffered an event of ventricular fibrillation, and was resuscitated. This arrhythmia was thought to be caused by an old infarct scar. She is treated with beta-blockers and amiodarone.

Proband's brother (II.4) is a 53-year-old male with no history of arrhythmias or other known cardiovascular disease. In the initial examination, cardiac MRI showed RV dilatation and microaneurysms in the inferior RV wall and near the RVOT, with an akinetic zone present inferiorly in the free wall. Septum was slightly hypokinetic and thickened, and in the apical septum there was signal change suggestive of myocardial fatty infiltration.

Screening of family 1 revealed altogether three homozygotes, six heterozygotes and one wild type individual (Fig. 2). All family members homozygote for the Thr335Ala fulfilled the criteria for definitive ARVC diagnosis, whereas none of the heterozygous carriers had findings relating to ARVC or any other cardiac disease. However, one of the index patient's children (III.2) has had a collapse of unknown etiology. The wild type homozygous sibling (II.7) has had paroxysmal atrial fibrillation. The index patient's mother, who was an obligatory heterozygous carrier of the mutation, had congestive heart failure stemming from myocardial infarction and chronic atrial fibrillation.

\section{Family 2}

Proband (II.1) is a 56-year-old male with ARVC. He had an event of acute chest pain at the age of 51 with elevated cardiac markers. Patient was initially treated as having a non-ST elevation myocardial infarction. Subsequent angiography showed no signs of major coronary artery disease. Thereafter, patient experienced episodes of sustained monomorphic VT. Cardiac MRI showed RV dilatation and free wall akinesia. LV was also dilated and thinning of LV myocardium and hypokinesia was present. VT was inducible in EPS, but catheter ablation was not performed. Diagnostic changes were not found in endomyocardial biopsy, although immunohistochemical stains showed borderline myocarditis by Dallas criteria. Patient has an ICD, and is treated with beta blockers.

Proband's brother (II.5) is 59 years old and has a history of atrial fibrillation, hypertension, hypercholesterolemia and three-vessel coronary artery disease with bypass surgery performed. Initially, cardiac MRI showed RV free wall microaneurysms, along with an RVOT aneurysm and apical dyssynchronous contraction (Fig. 3). RV was also slightly dilated and systolic function was diminished. During the follow up in a subsequent MRI, dilatation of the RV progressed markedly and the RVOT aneurysm also enlarged (diameter of $75 \mathrm{~mm}$ in axial plane). LV size and function was in the normal range, although it also underwent dilatation during the follow-up. Ventricular fibrillation was inducible in EPS, and ICD has been implanted.

Screening of family 2 revealed in total two homozygotes and three heterozygotes (Fig. 2). Again, both of the homozygotes fulfilled the criteria for definitive ARVC diagnosis. Heterozygote carriers had no symptoms relating to ARVC or any other cardiac disease. Neither of the index patient's parents' medical records showed any signs suggestive of cardiomyopathy. One of them is an obligatory heterozygous carrier of the mutation, while the other may either be heterozygous or homozygous for the variant.

\section{Discussion and conclusions}

Based on the families described in this study and the family published by Rasmussen et al. (see below) [19], 


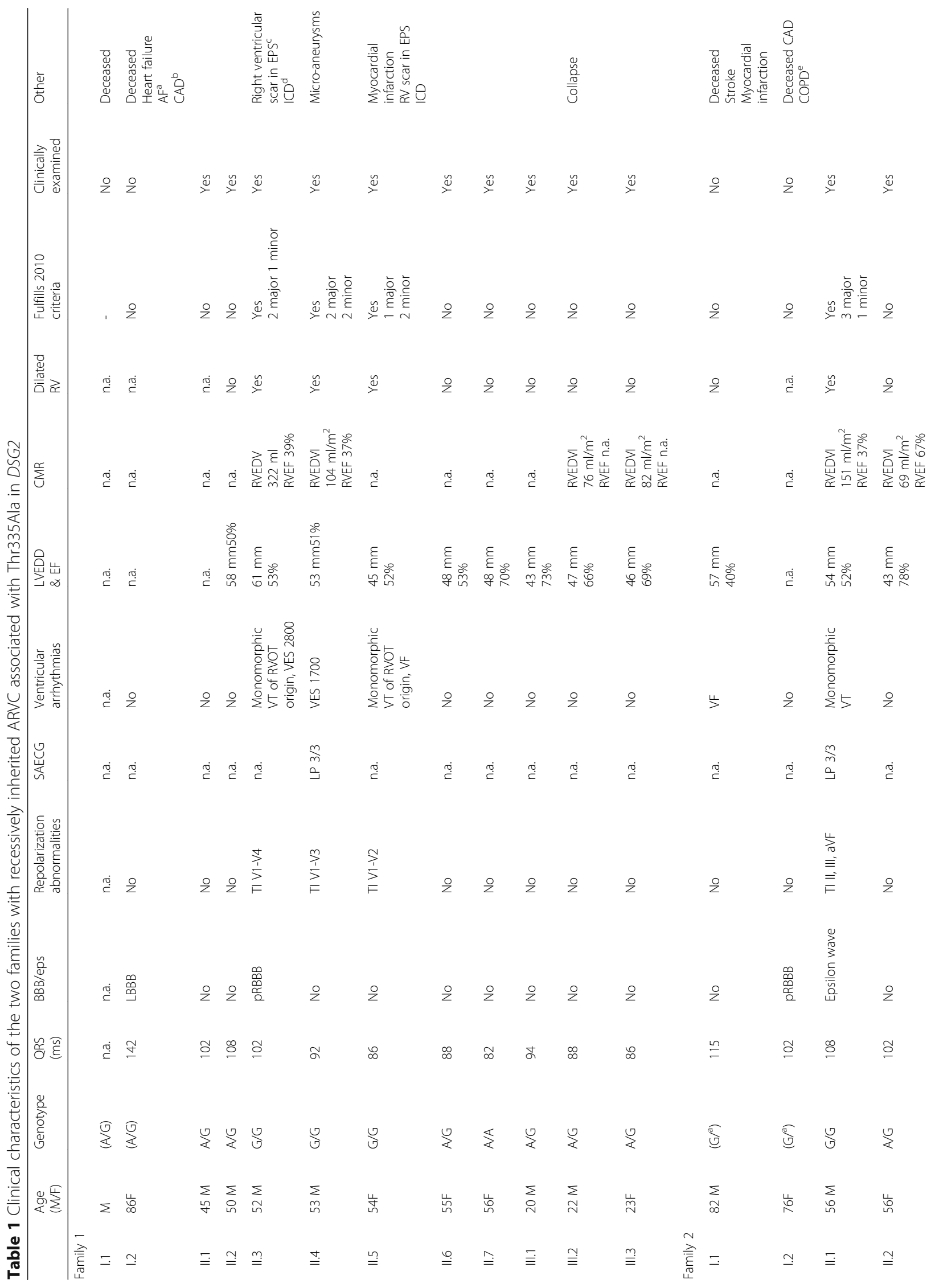




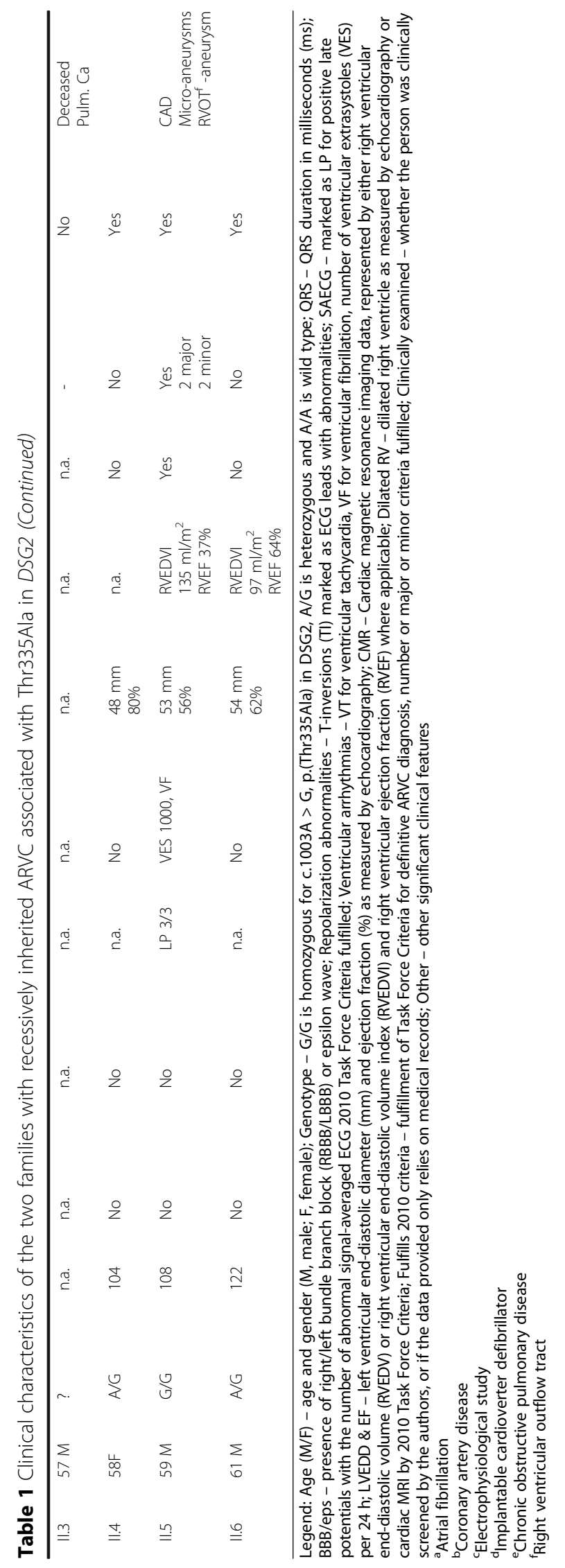



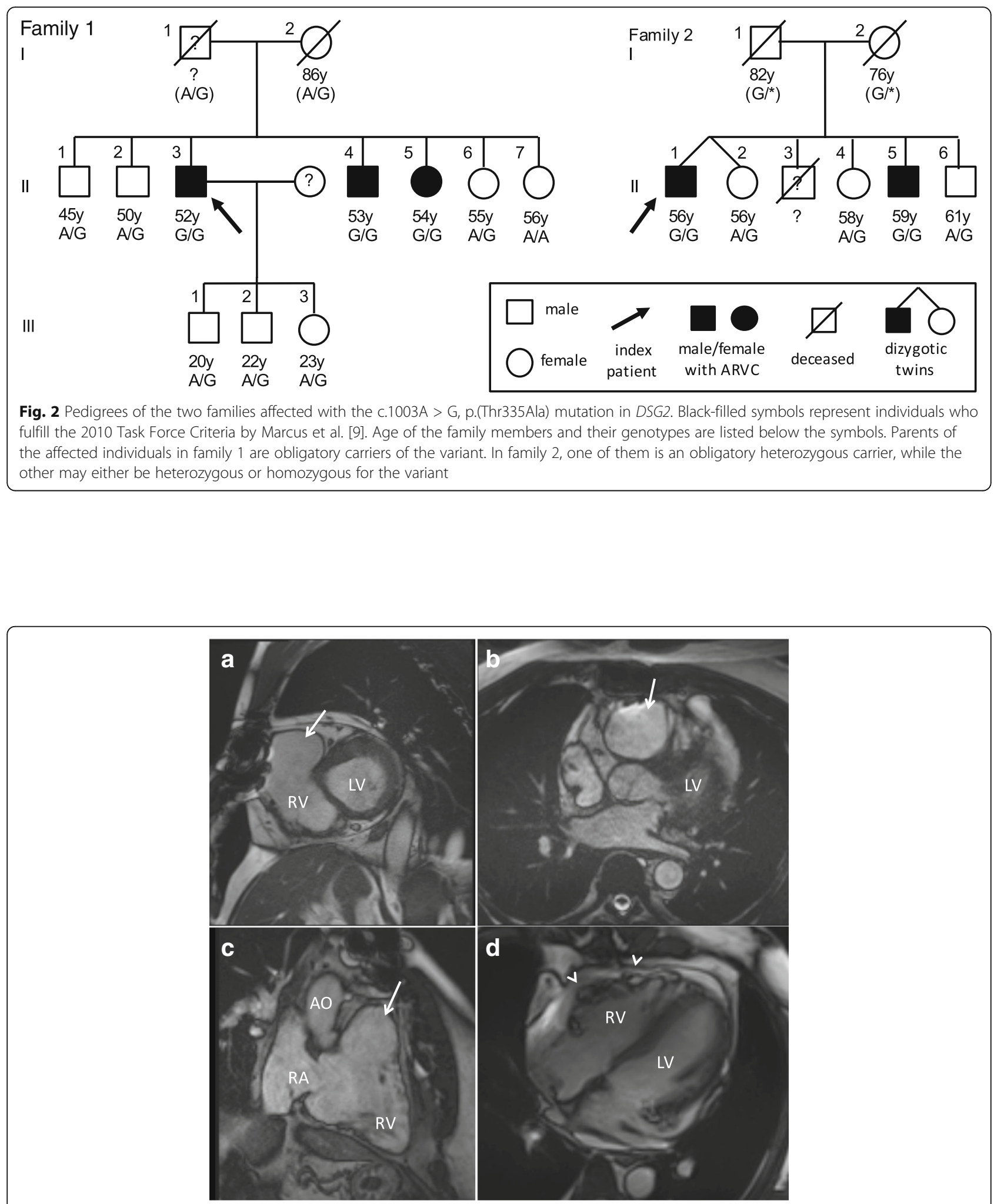

Fig. 3 Cardiac magnetic resonance images of a 59-year-old male homozygote for the Thr335Ala in DSG2 (II.5, family 2). Short-axis (a), axial (b) and right ventricular outflow tract (RVOT) (c) views of the heart show aneurysmal dilatation of the RVOT (arrows). Maximum dimension of the aneurysm was $67 \mathrm{~mm}$ and right ventricular end-diastolic volume index (RVEDVI) was $109 \mathrm{ml} / \mathrm{m}^{2}$. During follow-up, further dilatation of the aneurysm and the RV was observed. Four-chamber view shows rare microaneurysms in the right ventricular free wall (arrowheads) (d). LV = left ventricle; RV = right ventricle; $\mathrm{RVOT}=$ right ventricular outflow tract; $\mathrm{RA}=$ right atrium; $\mathrm{AO}=$ aorta 
the p.(Thr335Ala) in DSG2 associates with cardiomyopathy only in a homozygous state, as heterozygotes are considered healthy/not affected. This is consistent with recessive inheritance pattern. These findings highlight the importance of careful interpretation of the desmosomal variants. It seems that truly informative genetic counseling may require extensive clinical and genetic work-up in families with ARVC, especially when a variant is too common in control cohorts to be fully penetrant disease causing as heterozygote.

Rasmussen et al. have identified the same DSG2 variant in a family in which two brothers had severe ARVC [19]. These brothers were homozygous for the variant whereas their healthy parents and two healthy siblings were carriers, suggestive of recessive inheritance. Detailed protein investigations demonstrated that the Thr335Ala variant protein was expressed and incorporated into desmosomes.

In the literature and open databases, the Thr335Ala in DSG2 has been reported in $\geq 15$ patients with ARVC (ClinVar accession SCV000060918) [25, 26, 36-44]. Family segregation is rarely studied in these reports. At least six individuals with ARVC carried an additional pathogenic $P K P 2$ variant [36, 37, 40-42]. We have previously detected the same DSG2 variant as heterozygous in two patients and as homozygous in one patient. The homozygous patient was in his twenties with DCM, and did not carry any other variants considered significant for the phenotype. One heterozygous carrier was a boy who suffered sudden cardiac death, and the other was a female with clinically suspected DCM but who also carried Arg634His in DSC2 (classified as a variant of unknown significance).

The Thr335Ala has been reported in DCM patients in two studies $[20,45]$. In the first study the index patient had DCM, requiring heart transplantation at the age of 45 [20]. His brother was diagnosed with asymptomatic DCM at the age of 52. In addition to the Thr335Ala, both brothers carried p.(Glu1833Val) in DSP which is common in the ExAC reference population and likely has no effect on phenotype. Another brother (49y) and their mother's sister (76y) were also carriers of these variants and they were both healthy. Two other healthy siblings (47y and 55y) carried only the Thr335Ala variant. Therefore, DCM was diagnosed in $33 \%$ of the Thr335Ala carriers in the family. Other genetic factors were recognized that probably had a role in disease penetrance. In the other study, a DCM patient had both the Thr335Ala in DSG2 and Ala897fs"4 in DSC2 [45]. However, the $D S C 2$ variant is unlikely to contribute to the phenotype, as it is also common in the ExAC database and the frameshift leads to a stop codon in the normal position.

There have also been other homozygous DSG2 variants such as the p.(Val55Met) found in a DCM patient
[46]. His parents were both carriers of the mutation but only the father had DCM. However, the father's disease had later onset and a milder course. Immunostaining and electron microscopy of explanted LV wall myocardium from the homozygous proband revealed pale intercalated discs and significantly shorter desmosomes compared to wild-type myocardium. Unfortunately, no heterozygous carrier was studied by immunostaining. Severe disease in a patient with homozygous DSG2 mutation and a milder disease in a carrier may indicate a dosage effect of DSG2 mutations on cardiac function.

Variant interpretation is still challenging as earlier studies form major pitfalls by false classifications related to small reference populations, co-incidental segregations and evaluation of only a small subset of the potentially meaningful genes behind a patient's phenotype. In diagnostic laboratories and clinics, variant classification practices are largely based on recommendations by the American College of Medical Genetics and Genomics (ACMG) [47]. Without available family segregation data, variants are classified as pathogenic only when the genotype has been identified in a certain number of patients (e.g. 5-20) with the appropriate phenotype, or when the variant has occurred de novo multiple times in association with sporadic disease. Segregation analyses of large families are considered the best approach to define causativity of a variant and assess its penetrance. Largescale genetic research and variant sharing will eventually bring more consistency to the evaluation of families with inherited cardiac diseases.

\section{Additional file}

Additional file 1: Descriptions of the next generation sequencing (NGS) based large panels used in the initial genetic investigations of the index patients. (PDF $21 \mathrm{~kb}$ )

\section{Abbreviations \\ ARVC: Arrhythmogenic right ventricular cardiomyopathy; DCM: Dilated cardiomyopathy; DSC2: Desmocollin-2; DSG2: Desmoglein-2; DSP: Desmoplakin; ECG: Electrocardiography; EF: Ejection fraction; EPS: Electrophysiological study; ExAC: Exome aggregation consortium; ICD: Implantable cardioverter-defibrillator; JUP: Plakoglobin; LV: Left ventricle; MRI: Magnetic resonance imaging; NGS: Next generation sequencing; OS- Seq: Oligonucleotide-selective sequencing; PCl: Percutaneous coronary intervention; PKP2: Plakophilin-2; RV: right ventricle; RVOT: Right ventricular outflow tract; SAECG: Signal-averaged electrocardiography; TFC: Task Force Criteria; VT: Ventricular tachycardia}

\section{Acknowledgements}

We are grateful to the families for their participation in this study. We acknowledge RN Liisa Innamaa-Blubaum for her excellent assistance in data collection.

\section{Funding}

This study was supported by Special Governmental subsidy TYH2014208 (TH), EVO-fund Y2016SK003 (TH), Finnish Foundation for Cardiovascular Research (TH) and Aarne Koskelo Foundation (TH). 


\section{Availability of data and materials}

The datasets used and/or analyzed during the current study are available from the corresponding author on reasonable request.

\section{Authors' contributions}

SQ analyzed and interpreted the clinical data and wrote the manuscript. OA performed cardiologic investigations on the patients and participated in the writing of the manuscript. JV performed cardiologic investigations on the patients and participated in the writing of the manuscript. EHS contributed to the molecular genetic analyses of the study subjects and to the writing of the manuscript. SM contributed to the molecular genetic analyses of the study subjects and to the writing of the manuscript. TPA contributed to the molecular genetic analyses of the study subjects and to the data analysis and to the writing of the manuscript. MH performed the cardiac MRI analyses of the study subjects and contributed to the writing of the manuscript. TH contributed to the funding and study organization, the analysis of clinical data and to the writing of the manuscript. JWK contributed to study planning, funding, molecular genetic analyses, the analysis of clinical data, and to the writing of the manuscript. All authors read and approved the final manuscript.

\section{Ethics approval and consent to participate}

This study has been approved by The Ethical Review Committee of the Department of Medicine, University of Helsinki, and conforms to the ethical principles outlined in the Declaration of Helsinki. The subjects have signed a written informed consent for their participation to the study, and are at least 18 years of age.

\section{Consent for publication}

A written informed consent has been obtained from all study participants for the usage of patient data and images in publications.

\section{Competing interests}

Minor conflict of interest: JWK, TPA, and SM are co-founders of Blueprint Genetics, which offers genetic diagnostic services.

\section{Publisher's Note}

Springer Nature remains neutral with regard to jurisdictional claims in published maps and institutional affiliations.

\section{Author details}

${ }^{1}$ Heart and Lung Center HUH, University of Helsinki, Helsinki, Finland. ${ }^{2}$ Department of Cardiology, Päijät-Häme Central Hospital, Lahti, Finland. ${ }^{3}$ Blueprint Genetics, Helsinki, Finland. ${ }^{4}$ Institute of Biomedicine, University of Helsinki, Helsinki, Finland. ${ }^{5}$ Hospital for Children and Adolescents, Institute of Clinical Medicine, University of Helsinki, Helsinki, Finland. ${ }^{6}$ Department of Clinical Physiology and Nuclear Medicine, HUS Medical Imaging Center, Helsinki University Hospital and University of Helsinki, 00290 Helsinki, Finland.

\section{Received: 3 January 2017 Accepted: 13 July 2017}

\section{Published online: 17 August 2017}

\section{References}

1. Basso C, Bauce B, Corrado D, Thiene G. Pathophysiology of arrhythmogenic cardiomyopathy. Nat Rev Cardiol. 2012;9:223-33.

2. Marcus FI, Fontaine GH, Guiraudon G, Frank R, Laurenceau JL, Malergue C, et al. Right ventricular dysplasia: a report of 24 adult cases. Circulation. 1982; 65:384-98.

3. Nava A, Thiene G, Canciani B, Scognamiglio R, Daliento L, Buja G, et al, Familial occurrence of right ventricular dysplasia: a study involving nine families. J Am Coll Cardiol. 1988;12:1222-8.

4. Corrado D, Basso C, Thiene G, McKenna WJ, Davies MJ, Fontaliran F, et al. Spectrum of clinicopathologic manifestations of arrhythmogenic right ventricular cardiomyopathy/dysplasia: a multicenter study. J Am Coll Cardiol. 1997;30:1512-20.

5. Sen-Chowdhry S, Syrris P, Prasad SK, Hughes SE, Merrifield R, Ward D, et al. Left-dominant arrhythmogenic cardiomyopathy: an under-recognized clinical entity. J Am Coll Cardiol. 2008;52:2175-87.

6. Thiene G, Nava A, Corrado D, Rossi L, Pennelli N. Right ventricular cardiomyopathy and sudden death in young people. N Engl J Med. 1988; 318:129-33.
7. Corrado D, Thiene G, Nava A, Rossi L, Pennelli N. Sudden death in young competitive athletes: clinicopathologic correlations in 22 cases. Am J Med. 1990;89:588-96.

8. Virmani R, Burke AP, Farb A, Kark JA. Causes of sudden death in young and middle-aged competitive athletes. Cardiol Clin. 1997;15:439-66.

9. Marcus Fl, McKenna WJ, Sherrill D, Basso C, Bauce B, Bluemke DA, et al. Diagnosis of arrhythmogenic right ventricular cardiomyopathy/dysplasia: proposed modification of the task force criteria. Circulation. 2010;121:1533-41.

10. Rampazzo A, Nava A, Danieli GA, Buja G, Daliento L, Fasoli G, et al. The gene for arrhythmogenic right ventricular cardiomyopathy maps to chromosome 14q23-q24. Hum Mol Genet. 1994;3:959-62.

11. Peters S, Trümmel M, Meyners W. Prevalence of right ventricular dysplasiacardiomyopathy in a non-referral hospital. Int J Cardiol. 2004;97:499-501.

12. Sen-Chowdhry S, Syrris P, McKenna WJ. Genetics of right ventricular cardiomyopathy. J Cardiovasc Electrophysiol. 2005;16:927-35.

13. Campuzano O, Alcalde M, Allegue C, Iglesias A, Garcia-Pavia P, Partemi S, et al. Genetics of arrhythmogenic right ventricular cardiomyopathy. J Med Genet. 2013;50:280-9.

14. Nava A, Scognamiglio R, Thiene G, Canciani B, Daliento L, Buja G, et al. A polymorphic form of familial arrhythmogenic right ventricular dysplasia. Am J Cardiol. 1987:59:1405-9.

15. Protonotarios N, Tsatsopoulou A, Patsourakos P, Alexopoulos D, Gezerlis P, Simitsis $\mathrm{S}$, et al. Cardiac abnormalities in familial palmoplantar keratosis. $\mathrm{Br}$ Heart J. 1986;56:321-6.

16. Coonar AS, Protonotarios N, Tsatsopoulou A, Needham EWA, Houlston RS, Cliff S, et al. Gene for arrhythmogenic right ventricular cardiomyopathy with diffuse nonepidermolytic palmoplantar keratoderma and woolly hair (Naxos disease) maps to 17q21. Circulation. 1998;97:2049-58.

17. Simpson MA, Mansour S, Ahnood D, Kalidas K, Patton MA, McKenna WJ, et al. Homozygous mutation of desmocollin-2 in arrhythmogenic right ventricular cardiomyopathy with mild palmoplantar keratoderma and woolly hair. Cardiology. 2009;113:28-34.

18. Al-Sabeq B, Krahn AD, Conacher S, Klein GJ, Laksman Z. Arrhythmogenic right ventricular cardiomyopathy with recessive inheritance related to a new homozygous desmocollin-2 mutation. Can J Cardiol. 2014;30:696. e1-696.e3

19. Rasmussen TB, Palmfeldt J, Nissen PH, Magnoni R, Dalager $S$, Jensen UB, et al. Mutated desmoglein-2 proteins are incorporated into desmosomes and exhibit dominant-negative effects in arrhythmogenic right ventricular cardiomyopathy. Hum Mutat. 2013;34:697-705.

20. Garcia-Pavia P, Syrris P, Salas C, Evans A, Mirelis JG, Cobo-Marcos M, et al. Desmosomal protein gene mutations in patients with idiopathic dilated cardiomyopathy undergoing cardiac transplantation: a clinicopathological study. Heart. 2011:97:1744-52.

21. Elliott P, O'Mahony C, Syrris P, Evans A, Rivera Sorensen C, Sheppard MN, et al. Prevalence of desmosomal protein gene mutations in patients with dilated cardiomyopathy. Circ Cardiovasc Genet. 2010;3:314-22.

22. Akinrinade O, Ollila L, Vattulainen S, Tallila J, Gentile M, Salmenpera P, et al. Genetics and genotype-phenotype correlations in Finnish patients with dilated cardiomyopathy. Eur Heart J. 2015;36:2327-37.

23. Bauce B, Nava A, Beffagna G, Basso C, Lorenzon A, Smaniotto G, et al. Multiple mutations in desmosomal proteins encoding genes in arrhythmogenic right ventricular cardiomyopathy/dysplasia. Heart Rhythm. 2010;7:22-9.

24. Quarta G, Syrris P, Ashworth M, Jenkins S, Zuborne Alapi K, Morgan J, et al. Mutations in the Lamin a/C gene mimic arrhythmogenic right ventricular cardiomyopathy. Eur Heart J. 2012;33:1128-36.

25. James CA, Bhonsale A, Tichnell C, Murray B, Russell SD, Tandri H, et al. Exercise increases age-related Penetrance and arrhythmic risk in Arrhythmogenic right ventricular dysplasia/Cardiomyopathy-associated Desmosomal mutation carriers. J Am Coll Cardiol. 2013;62:1290-7.

26. Xu T, Yang Z, Vatta M, Rampazzo A, Beffagna G, Pilichou K, et al. Compound and digenic heterozygosity contributes to arrhythmogenic right ventricular cardiomyopathy. J Am Coll Cardiol. 2010;55:587-97.

27. Rigato I, Bauce B, Rampazzo A, Zorzi A, Pilichou K, Mazzotti E, et al. Compound and digenic heterozygosity predicts lifetime arrhythmic outcome and sudden cardiac death in desmosomal gene-related arrhythmogenic right ventricular cardiomyopathy. Circ Cardiovasc Genet. 2013;6:533-42.

28. Bhonsale A, Groeneweg JA, James CA, Dooijes D, Tichnell C, Jongbloed JDH, et al. Impact of genotype on clinical course in arrhythmogenic right ventricular dysplasia/cardiomyopathy-associated mutation carriers. Eur Heart J. 2015;36: $847-55$. 
29. Pinto YM, Elliott PM, Arbustini E, Adler Y, Anastasakis A, Bohm M, et al. Proposal for a revised definition of dilated cardiomyopathy, hypokinetic non-dilated cardiomyopathy, and its implications for clinical practice: a position statement of the ESC working group on myocardial and pericardial diseases. Eur Heart J. 2016;37:1850-8.

30. Myllykangas S, Buenrostro JD, Natsoulis G, Bell JM, Ji HP. Efficient targeted resequencing of human germline and cancer genomes by oligonucleotideselective sequencing. Nat Biotechnol. 2011;29:1024-7.

31. Adzhubei IA, Schmidt S, Peshkin L, Ramensky VE, Gerasimova A, Bork P, et al. A method and server for predicting damaging missense mutations. Nat Methods. 2010;7:248-9.

32. Schwarz JM, Cooper DN, Schuelke M, Seelow D. MutationTaster2: mutation prediction for the deep-sequencing age. Nat Methods. 2014;11:361-2.

33. $\mathrm{Ng} \mathrm{PC}$, Henikoff S. Predicting deleterious amino acid substitutions. Genome Res. 2001;11:863-74.

34. The 1000 Genomes Project Consortium. A global reference for human genetic variation. Nature. 2015;526:68-74.

35. Lek M, Karczewski KJ, Minikel EV, Samocha KE, Banks E, Fennell T, et al. Analysis of protein-coding genetic variation in 60,706 humans. Nature. 2016;536:285-91.

36. den Haan AD, Tan BY, Zikusoka MN, Llado LI, Jain R, Daly A, et al. Comprehensive desmosome mutation analysis in north americans with arrhythmogenic right ventricular dysplasia/cardiomyopathy. CirculationCardiovascular Genetics. 2009;2:428-35.

37. Tan BY, Jain $R$, den Haan AD, Chen Y, Dalal D, Tandri $H$, et al. Shared desmosome gene findings in early and late onset arrhythmogenic right ventricular dysplasia/cardiomyopathy. J Cardiovasc Transl Res. 2010;3:663-73.

38. Christensen AH, Benn M, Bundgaard H, Tybjaerg-Hansen A, Haunso S, Svendsen $\mathrm{JH}$. Wide spectrum of desmosomal mutations in Danish patients with arrhythmogenic right ventricular cardiomyopathy. J Med Genet. 2010;47:736-44.

39. Quarta G, Muir A, Pantazis A, Syrris P, Gehmlich K, Garcia-Pavia P, et al. Familial evaluation in arrhythmogenic right ventricular cardiomyopathy: impact of genetics and revised task force criteria. Circulation. 2011;123:2701-9.

40. Cox MG, van der Zwaag PA, van der Werf C, van der Smagt JJ, Noorman M, Bhuiyan ZA, et al. Arrhythmogenic right ventricular dysplasia/ cardiomyopathy: pathogenic desmosome mutations in index-patients predict outcome of family screening: Dutch arrhythmogenic right ventricular dysplasia/cardiomyopathy genotype-phenotype follow-up study. Circulation. 2011;123:2690-700.

41. Riele T, Anneline SJM, James CA, Philips B, Rastegar N, Bhonsale A Groeneweg JA, et al. Mutation-positive arrhythmogenic right ventricular dysplasia/cardiomyopathy: the triangle of dysplasia displaced. J Cardiovasc Electrophysiol. 2013;24:1311-20.

42. Bhonsale A, James CA, Tichnell C, Murray B, Madhavan S, Philips B, et al. Risk stratification in arrhythmogenic right ventricular dysplasia/cardiomyopathyassociated desmosomal mutation carriers. Circulation: Arrhythmia and Electrophysiology. 2013;6:569-78.

43. Philips B, Madhavan S, James CA, te Riele AS, Murray B, Tichnell C, et al. Arrhythmogenic right ventricular dysplasia/cardiomyopathy and cardiac sarcoidosis: distinguishing features when the diagnosis is unclear. Circ Arrhythm Electrophysiol. 2014:7:230-6.

44. van der Zwaag PA, Jongbloed JDH, van den Berg MP, van der Smagt JJ, Jongbloed $\mathrm{R}$, Bikker $\mathrm{H}$, et al. A genetic variants database for arrhythmogenic right ventricular dysplasia/cardiomyopathy. Hum Mutat. 2009;30:1278-83.

45. Pugh TJ, Kelly MA, Gowrisankar S, Hynes E, Seidman MA, Baxter SM, et al. The landscape of genetic variation in dilated cardiomyopathy as surveyed by clinical DNA sequencing. Genet Med. 2014;16:601-8.

46. Posch MG, Posch MJ, Geier C, Erdmann B, Mueller W, Richter A, et al. A missense variant in desmoglein-2 predisposes to dilated cardiomyopathy. Mol Genet Metab. 2008:95:74-80.

47. Richards S, Aziz N, Bale S, Bick D, Das S, Gastier-Foster J, et al. Standards and guidelines for the interpretation of sequence variants: a joint consensus recommendation of the American College of Medical Genetics and Genomics and the Association for Molecular Pathology. Genet Med. 2015;17:405-24.

\section{Submit your next manuscript to BioMed Central and we will help you at every step:}

- We accept pre-submission inquiries

- Our selector tool helps you to find the most relevant journal

- We provide round the clock customer support

- Convenient online submission

- Thorough peer review

- Inclusion in PubMed and all major indexing services

- Maximum visibility for your research

Submit your manuscript at www.biomedcentral.com/submit
Biomed Central 